\title{
The Paradigm Shift from Financial Reporting to Integrated Reporting
}

\author{
Kazunori Ito ${ }^{1}$, Masaki Iijima ${ }^{2, *}$ \\ ${ }^{1}$ Department of Accounting, Faculty of Commerce, Senshu University, Kawasaki, Japan \\ ${ }^{2}$ Department of Management, Faculty of Management, Aichi Gakuin University, Nagoya, Japan \\ E-mail address: \\ thc0724@isc.senshu-u.ac.jp (K. Ito), iijima@dpc.agu.ac.jp (M. Iijima) \\ ${ }^{*}$ Corresponding author
}

To cite this article:

Kazunori Ito, Masaki Iijima. The Paradigm Shift from Financial Reporting to Integrated Reporting. Journal of Human Resource Management. Vol. 6, No. 3, 2018, pp. 85-91. doi: 10.11648/j.jhrm.20180603.11

Received: September 12, 2018; Accepted: October 12, 2018; Published: November 1, 2018

\begin{abstract}
In Japan, many companies are preparing integrated reports. Under such circumstances, some companies prepare annual reports as an integrated report. Nevertheless, the views on the essence of the integrated report are not always agreed upon. Some companies are preparing annual reports or sustainability reports as integrated reports. Thus, some researchers insist on the integrated report as being useful for investors. On the other hand, some researchers proposed that the integrated report is useful for stakeholders. This paper discusses the essence of integrated reports and who they might be useful for. The aim of this paper is to propose our opinion about the essence of integrated reports. This paper clarifies some views on the integrated reports and used a literature review methodology to propose our view. As a result of the literature research, it was found that the essence of the integrated report is to disclose not only financial information but also non-financial information. This point is a significant difference from the annual report. In addition, the integrated report is not disclosed only to investors, but was found to be strongly influenced by the idea of the sustainability report in terms of stakeholder engagement. In short, what this paper wanted to point out is that integrated reporting can be used not only as information disclosure to stakeholders but also as information usage for strategy formulation and business management through stakeholder engagement.
\end{abstract}

Keywords: Paradigm Shift, Integrated Reports, Financial Reports, Sustainability Reports, Inside-Out Approach

\section{Introduction}

Many corporations have started to release integrated reports in Japan. Releasing integrated reports is catching on in Japan with Takara Printing announcing that 334 corporations released integrated reports as well as Edge International announcing 277 as of the end of December 2016 (The data from Edge International and Takara Printing can be downloaded from the URLs:http://cvrl-net.com/archive/index.html (2017/2/22) and http://rid.takara-printing.jp/esg/ (2017/2/22)). Depending on the corporation, the term "integrated report" is not necessarily used. Some corporations release their integrated reports as annual reports. There are also corporations that release their integrated reports as sustainability reports. Companies are free to call their reports as they like, but there are various differences in these corporate reports.

Financial reports such as annual reports disclose financial information, while sustainability reports disclose non-financial information. Integrated reports disclose both financial and non-financial information. In this way, even just in terms of the information disclosed, there is a major difference in the three types of corporate reports. Herein Koga [15] pointed out that the issue is whether integrated reports are useful for investors or stakeholders. For example, some researcher proposed different opinions about how to prepare integrated report. Kraten [14] insisted on preparing the relationship of the Octopus Model of IIRC with on information system. He proposed the integrated report for investors. Mark and Thomas [16] proposed a development of MulatiCapital Scorecard for preparing sustainability reports for stakeholders. On the other hand, Ito and Nishihara [23] proposed Strategy Maps for visualizing Value Creation in the integrated report for stakeholders. Thus, there are some opinions regarding the essence of integrated reports. This point is a part that does not see agreement of views among 
researchers. The aim of this paper is to find the essence of integrated reports. At the same time, this paper will clarify the paradigm shift in corporate reports by examining the essential differences in these three types of corporate reports.

The aim of this paper is to clarify the target audience and purpose for reporting as the essence of integrated reporting. This paper will clarify whether investors are the main target audience and information disclosure to investors is the reporting purpose or whether stakeholders are the main target audience and engagement, the reporting purpose. It will further clarify whether the aim of stakeholder engagement is information disclosure or information usage by internal managers. The first section will clarify the issues of integrated reports. The second section will explore the aim of integrated reports according to the IIRC. The third section will shed light on the views of Fasan and Barker and Kasim, who discuss the similarities between financial reports and integrated reports and the views of Stubbs and Higgins, who point out the significance of integrated reporting to managers. The fourth section will review the target audience and purpose for reporting and propose the ideal form of the integrated reports. Lastly, this paper will summarize the findings made in this paper.

\section{Issues of Integrated Reports}

External reports by corporations (hereinafter referred to as "corporate reports"), as represented by annual reports, center on financial reports. Such financial reports can objectively report on the financial situation and management performance of a corporation, but there remains an issue that they do not take up the problems of society or the environment. Therefore, many corporations voluntarily compile and release environmental reports, corporate social responsibility (CSR) reports, or sustainability reports (hereinafter collectively represented by sustainability reports) separately from their financial reports. Even though a corporation may release both a financial report and sustainability report, because the information in the two reports is not coherent, they may not be useful to the decision-making of investors or disclose the information that stakeholders need.

In order to integrate financial reports and sustainability reports, the International Integrated Reporting Council (IIRC) released an integrated reporting framework [13]. Since 2013, the number of corporations in Japan releasing integrated reports has increased dramatically. Such corporations not only release financial information, but also non-financial information under the same title of annual report or sustainability report. Following the value creation model proposed by the IIRC, a substantial number of corporations are also releasing integrated reports.

As the essence of integrated reports, there is a view that integrated reports are considered to be akin to financial reports in a sense that the target audience of integrated reports is investors, to whom information is disclosed [3], [9]. On the other hand, there is the view that the reporting purpose of integrated reports is stakeholder engagement and therefore, financial reports are different from integrated reports and are an expansion of sustainability reports [20]. These views indicate that there is no consensus in views on the target audience and purpose for reporting.

Here this paper will be looking at the conflicting views on the target audience and purpose for reporting from a different perspective. As a result of comparing integrated reports and sustainability reports, there is literature that clarifies the advantages and disadvantages of integrated reports as follows: (1) they provide future information to investors [2], [21], (2) they allow managers to make decisions that control reputation risk [11], (3) they allow managers to improve business activities and their reporting system and processes [17], and (4) they allow managers to improve resource distribution [10]. One disadvantage of integrated reports is pointed out that (5) the problem of integrated reports is that they penalize stakeholders other than investors [6].

Among the above advantages and disadvantages, it should be noted in relation to the target audience of integrated reports that while the target audience in (1) is investors, (5) takes up stakeholders. Additionally, with regard to the reporting purpose, while (1) takes up information disclosure to investors, (2) to (4) take up the purpose of managers' business management and (5) takes up stakeholder engagement. In short, there is an issue of whether the target audience of integrated reporting is investors or stakeholders. This issue is closely connected with the reporting purpose of integrated reports and whether the reporting purpose is information disclosure to investors or stakeholder engagement is also an issue. Another issue is whether the aim of stakeholder engagement is information disclosure or to be of use to managers' business management.

\section{Aim of Integrated Reports According to the IIRC}

While according to the IIRC, the target audience of integrated reports is "the providers of financial capital" [13], it also states that they are beneficial to stakeholders such as "employees, customers, suppliers, business partners, local communities, legislators, regulators and policy-makers" [13]. Moreover, the IIRC elucidates the purpose of integrated reports to be "concise communication about how an organization's strategy, governance, performance and prospects, in the context of its external environment, lead to the creation of value over the short, medium and long term" [13]. The above indicates that the IIRC does not limit the purpose of integrated reports to be information provision to investors, but rather, considers them to be engagement with stakeholders on value creation.

The IIRC points out several limitations to conventional investor-oriented financial reports. For example, the council criticizes financial reports for being focused on past financial information and that financial reports and sustainability reports have no relation. Therefore, the IIRC [13] identifies four aims of integrated reports: to improve the quality of information available to providers of financial capital, to 
promote a more cohesive and efficient approach to corporate reports that draws on different reporting strands, to promote understanding of capitals, and to support integrated thinking.

The first aim, to improve the quality of information available to providers of financial capital, refers to connecting financial and non-financial information to make it possible for investors to obtain information that contributes to their decision-making. The main target audience according to the IIRC is providers of financial capital, in other words, investors. Annual reports are restricted to disclosing past financial information as information to investors. However, not only annual reports, but also non-financial information that could impact future financial performance, such as environment, social, and governance (ESG) information, is required to be disclosed.

The second aim, to promote a more cohesive and efficient approach to corporate reporting that draws on different reporting strands, means to disclose value creation by connecting annual reports with sustainability reports, which have been released without any linkage between them. Such disclosure is not only desired by investors and is also useful to stakeholders; for example, shareholders, financial institutions, customers, local communities, and employees who are impacted by the strategies of a specific corporation. Such stakeholders would want to get strategy information and if possible, would want to have dialog with the corporation.

The third aim, to promote understanding of capitals, means to disclose the results of a corporation's business activities as a broad base of capitals (financial, manufactured, intellectual, human, social and relationship, and natural) and make their interdependencies clear. By disclosing that the capital at the beginning of the term turns into the capital at the end of the term, an integrated report not only fulfills the corporation's accountability to shareholders, but stewardship responsibilities through stakeholder engagement. Additionally, by engaging with stakeholders in relation to the value creation process that impacts the interdependencies between capitals, the corporation can fulfill its accountability. By clarifying the interdependencies between capitals, the concepts of accountability and stewardship limited to shareholders and investors will be expanded, thereby fulfilling accountability and stewardship to stakeholders.

The fourth aim, integrated thinking, refers to disclosing information with a focus on a corporation's short, medium, and long-term value creation. Annual reports only disclose past financial information. On the other hand, integrated reporting is required to include the financial information of annual reports and non-financial information of sustainability reports for disclosure in relation to the short, medium, and long-term value creation process. Integration through the value creation process is the essence of integrated reports.

In short, the IIRC has awareness that financial reports have a problem and that instead of simply incorporating non-financial information, both financial information and non-financial information should be integrated. By proposing integrated reports here, this paper shows that the IIRC makes stakeholder engagement, rather than just information provision to investors, the reporting purpose of integrated reports.

\section{Comparative Study of Corporate Reports}

Fasan [9] and Barker and Kasim [3] opine in their studies that integrated reports are in essence the same as financial reports in the sense that they both disclose information to investors. Conversely, Stubbs and Higgins [20] argue that integrated reports differ from financial reports and are something that has expanded from sustainability reports. This section will clarify these arguments.

\subsection{Comparative Study of Corporate Reports by Fasan}

In order to reveal what the essence of an integrated report is, Fasan [9] compared and reviewed annual reports, sustainability reports, and integrated reports. Fasan compared the reports from seven items: target audience, mandatory/voluntary, regulations/guidelines, comparability, customization by business category, level of guarantee and perspectives. Table 1 summarizes them.

Annual reports, information disclosure to shareholders and investors, are regulated by accounting standards, etc., in order to be able to compare the corporation with other corporations, and therefore, have a high level of guarantee. However, one criticism of annual reports is that they do not reflect changes in the economic situation and lack reliability and clarity [7]. For example, British Petroleum, which caused the Gulf of Mexico oil spill in 2010, did not include information that acknowledged the potential danger in its financial reports until the incident occurred. From this example, this paper shows that while the complexity of corporations is increasing, the reliability of financial reports is falling. Additionally, financial reports rarely provided non-financial information on management quality, degree of customer satisfaction, environmental and social achievements, etc.

Table 1. Comparison of Three Corporate Reports by Fasan.

\begin{tabular}{|c|c|c|c|}
\hline Item 2 Report & Financial Reports & Sustainability Reports & Integrated Reports \\
\hline Target Audience & $\begin{array}{l}\text { Specific stakeholders (shareholders } \\
\text { and investors) }\end{array}$ & $\begin{array}{l}\text { Diverse stakeholders (social and } \\
\text { environmental perspective) }\end{array}$ & Mainly providers of financial capital \\
\hline Mandatory/Voluntary & Mandatory & $\begin{array}{l}\text { Voluntary (exceptions are Denmark, Sweden, } \\
\text { and France) }\end{array}$ & Voluntary (exception is South Africa) \\
\hline Regulations/Guidelines & $\begin{array}{l}\text { Domestic and international laws and } \\
\text { GAAP (or IAS/IFRS) }\end{array}$ & Global Reporting Initiative (GRI) & IIRC Framework \\
\hline Customization by & Low & Medium (supplemental business category & Low \\
\hline
\end{tabular}




\begin{tabular}{|c|c|c|c|}
\hline $\begin{array}{ll}\text { Item } & \text { Report } \\
\end{array}$ & Financial Reports & Sustainability Reports & Integrated Reports \\
\hline Business Category & & material) & \\
\hline Level of Guarantee & High & Low & Low \\
\hline Perspective & $\begin{array}{l}\text { Reporting entity (corporations and } \\
\text { corporate groups) }\end{array}$ & $\begin{array}{l}\text { Broader than the reporting entity (supply } \\
\text { chain, LCA approach) }\end{array}$ & $\begin{array}{l}\text { Broader than the reporting entity } \\
\text { (supply chain, LCA approach) }\end{array}$ \\
\hline
\end{tabular}

Source: Fasan [9].

Because such non-financial information can impact future financial performance, it is also useful to investors who are interested only in a corporation's financial performance. Additionally, financial reports also have the limitation of not being able to predict a corporation's future performance. This is because financial reports only report past financial performance and do not disclose information on the projections of future performance. However, Fasan [9] makes an interesting point that financial reports are used not only by investors, but also by corporate managers to make decisions on resource distribution This paper presumes that while there must be cases in which information on projections of future performance is disclosed, it must be because trying to achieve such projections influences resource distribution.

Sustainability reports provide information on a corporation's activities, passion, and public image towards issues related to the environment, community, employees, and customers. They contain numerous detailed issues such as the energy usage, equal opportunity, fair trade, and corporate governance. Depending on the concept of stakeholder, or by breaking down the boundaries of a report, there is great interest shown in problems that can impact a corporation's ability with regard to the long-term creation of value. In order to set a framework for sustainability reports, the Global Reporting Initiative (GRI) was established in 1997. In 2013, the GRI published the G4 Guidelines. G4 offers the options of reporting from strategically narrowed-down aspects and reporting comprehensively (GRI, 2013).

\subsection{Comparative Study of Corporate Reports by Barker and Kasim}

Owen [18] states that the origin of integrated reports goes back to the 1970s. The UK Accounting Standard Steering
Committee emphasized in its 1975 The Corporate Report [1] (The report can be downloaded from the URL: https://www.icaew.com/-/media/corporate/files/library/subjec ts/corporate-governance/corporate-report.ashx?la=en (2017/4/8)) a user-oriented perspective, rather than a shareholder-oriented or financial stewardship-oriented perspective. The user-oriented perspective here refers to interested parties such as financial institutions, employees, customers, suppliers, local residents, and the general public. Examples of such reports include CSR reports, environmental reports, and sustainability reports. The GRI framework is the most pervasive standard for such reports [3].

Baker and Kasim [3] used such databases as the EBSCOhost Business Source Complete, Elsevie SD Freedom Collection and ProQuest ABI/INFORM Global and searched for the keywords "integrated reporting," "IR framework," and "IIRC." This turned up 35 papers which were surveyed, resulting in bringing to light several differences in financial reports, integrated reports, and sustainability reports. A comparison of these three types of reports is shown in Table 2.

From the 35 papers, Barker and Kasim compiled a comparison chart of the three types of reports as shown in Table 2. The table compares five points, value, materiality, stakeholder engagement, reporting purpose, and impact on social capital and natural capital.

Table 2 shows that in terms of corporate value, financial reports are a function of financial capital, while integrated reports are a function of six capitals, and for sustainability reports natural capital alone is a negative function. The diagram points out that while there is a major discrepancy between financial reports and integrated reports, the view on corporate value in integrated reports and sustainability reports are similar.

Table 2. Comparison of Three Types of Corporate Reports by Barker and Kasim.

\begin{tabular}{|c|c|c|c|}
\hline Item $\quad$ Report & Financial Reports & Sustainability Reports & Integrated Reports \\
\hline Corporate Value & Function of financial capital & Natural capital is a negative function & Function of six capitals \\
\hline Materiality & & Natural materiality & Financial materiality \\
\hline Range of Sustainability & Sustainable profits (earnings) & Ideal sustainability & Integrated sustainability \\
\hline Corporate Strategy & Financial strategy & Socially responsible corporation & Sustainable strategy \\
\hline Stakeholder engagement & & Dialogic accounting & Integrated decision-making \\
\hline Experts' Value & $\begin{array}{l}\text { Person in charge of strategic } \\
\text { accounting }\end{array}$ & $\begin{array}{l}\text { Expertise of social and environmental } \\
\text { accounting }\end{array}$ & Person in charge of strategic accounting \\
\hline Reporting Purpose & Investors' information needs & Stakeholder maintenance & Appeal to long-term investors \\
\hline Impact on Financial Capital & $\begin{array}{l}\text { Financial and capital market } \\
\text { performance }\end{array}$ & $\begin{array}{l}\text { "All costs" accounting (triple depreciation } \\
\text { line) }\end{array}$ & $\begin{array}{l}\text { Financial and capital market } \\
\text { performance }\end{array}$ \\
\hline $\begin{array}{l}\text { Impact on Social and Natural } \\
\text { Capitals }\end{array}$ & & Social and environmental burden & $\begin{array}{l}\text { Environment, society, and governance } \\
\text { (ESG) performance }\end{array}$ \\
\hline Impact on Regulations & Institutional determinants & Social and political analysis & Institutional determinants \\
\hline
\end{tabular}

Source: compiled by the author based on Barker and Kasim [3]. 
Materiality refers to material facts to be disclosed. In a financial report account items can be grouped up if they have no monetary importance, but it does not handle materiality with regard to items to disclose in particular. In Table 2, materiality points to material factors that impact the environment in sustainability reports, while it points to material factors that impact finance in integrated reports. For example, in sustainability reports, materiality refers to points such as environmental pollution, natural disasters, and human rights protection. On the other hand, in integrated reports, it refers to strategic materiality such as how current facts may impact future corporate value, not necessarily limited to financial performance.

With regard to stakeholder engagement, financial reports do not focus on it at all. On the other hand, Table 2 shows the difference between sustainability reports and integrated reports in that while sustainability reports aim for dialogic accounting, integrated reports aim for integrated decision-making. This view comes from the publication of Brown and Dillard [4]. Because stakeholder engagement is relevant to the following reporting purpose, this paper will review it along with the reporting purpose.

The reporting purpose of financial reports according to Table 2 is response to the information needs of investors. Additionally, while sustainability reports concern maintaining stakeholders, integrated reports concern appealing to long-term investors. The argument of Barker and Kasim is that the reporting purpose of both financial reports and integrated reports is to disclose information or appeal to investors. The reporting purpose of sustainability reports is to maintain stakeholders.

Lastly, this paper will compare and review the impact on social and natural capitals. Financial reports need not state the impact on social capital or natural capital. Conversely, sustainability reports must report on the impact on social and natural capitals such as social and environmental burdens. In integrated reports social, environmental and governance information must also be disclosed reflecting ESG performance. From the above, this paper shows that sustainability reports and integrated reports are quite similar.

\subsection{Comparative Study of Corporate Reports by Stubbs and Higgins}

The interpretation of Stubbs and Higgins on the relationship between integrated reports and sustainability reports differs greatly from that of Fasan or Barker and Kasim. They point out that "integrated reports are the next phase of sustainability reports" [20]. From this, this paper shows their argument to mean that financial reports evolve to integrated reports through the phase of sustainability reports. Additionally, because unlike sustainability reports, integrated reports are closely linked to business strategy and value creation, they are said to be the "next phase." Stubbs and Higgins [20] consider that in the integrated report phase, unlike with sustainability reports, stakeholder engagement can be used as information for strategy formulation. Based on the hypothesis that organizational change is driven by integrated reports, Stubbs and Higgins conducted an interview survey. The target of the survey was major corporations in Australia and 23 persons at 15 corporations at different stages of introducing integrated reports were interviewed. The interview results are clarified below.

Through the interviews, they gained new findings on six items: a push/pull approach, cross-functional team, sustainability committees, department responsible for creating integrated reports, materiality, integrated measurement system and metrics.

The three types of corporate reports compared according to the six items taken up by Stubbs and Higgins [20] are shown in Table 3. This Table was not created by Stubbs and Higgins; this paper compiled the table based on the findings of Stubbs and Higgins [20].

Table 3. Comparison of Three Types of Corporate Reports based on the Study by Stubbs and Higgins.

\begin{tabular}{|c|c|c|c|}
\hline Item Report & Financial Report & Sustainability Report & Integrated Report \\
\hline Push/Pull Approach & Pull approach & Pull approach & Push approach \\
\hline Cross-Functional Team & $\begin{array}{l}\text { Single department such as the finance } \\
\text { department }\end{array}$ & $\begin{array}{l}\text { Single department such as the } \\
\text { sustainability department }\end{array}$ & Cross-functional team \\
\hline Sustainability Committee & Unnecessary & $\begin{array}{l}\text { Sustainability committee centered } \\
\text { on the sustainability office }\end{array}$ & $\begin{array}{l}\text { Integrated report committee comprising } \\
\text { members from the IR office, strategy } \\
\text { planning office, PR department, etc. }\end{array}$ \\
\hline Ownership of Reports & Financial department & Sustainability office & Integrated report office \\
\hline Materiality & Not concerned & $\begin{array}{l}\text { Materiality for the natural } \\
\text { environment and society }\end{array}$ & Materiality for strategic issues \\
\hline $\begin{array}{l}\text { Integrated Measurement } \\
\text { System and Metrics }\end{array}$ & $\begin{array}{l}\text { Financial information complying with } \\
\text { accounting standards and regulations }\end{array}$ & $\begin{array}{l}\text { Non-financial information such as } \\
\text { ESG information }\end{array}$ & $\begin{array}{l}\text { Financial and non-financial information } \\
\text { related to the value creation process }\end{array}$ \\
\hline
\end{tabular}

Source: compiled by the author based on Stubbs and Higgins [20].

As for push and pull approaches, financial reports, based on clear-cut accounting standards, are a pull- approach type and integrated reports, which disclose corporate strategies, are a push-approach type. In this sense, sustainability reports are a pull-approach type up to G3.1 of GRI, but at G4, a push-approach type. As shown in Table 3, Stubbs and Higgins point out that, premised on being up to G3.1, sustainability reports are a pull-approach type. Cross-functional teams are 
not considered in making financial reports, but are essential in compiling integrated reports. Sustainability reports are compiled by the department in charge (a sustainability department, for example). Similarly, a sustainability committee is necessary for compiling sustainability reports, but is unnecessary for financial reports or integrated reports.

The departments in charge of compiling financial reports are finance, accounting, and IR departments. Sustainability reports are created and released by departments in charge such as sustainability, CSR, or PR departments. On the other hand, IR or CSR departments usually take charge of integrated reports and it is necessary to design a dedicated department such as an integrated report department. Financial reports are not concerned with materiality. For sustainability reports and integrated reports, the concept of materiality is one of the keywords. Materiality for sustainability reports refers to materiality in the sense that they have a social and environmental impact while for integrated reports it refers to strategic materiality related to the creation of value. Lastly, when it comes to the integrated measurement system and metrics, financial reports include financial information while sustainability reports include non-financial ESG information. In this sense, they are not integrated. On the other hand, financial and non-financial information are integrated in integrated reports.

Stubbs and Higgins state that as a result of the interviews with 15 corporations that have introduced integrated reports, none had reached organizational changes. The reason for this was "because they were in the early stages of adopting integrated reports, it takes time for organizational changes" [20]. Therefore, they concluded that while integrated reports had the potential to drive future organizational change, information disclosure in the form of integrated reports had only just started and had not yet resulted in organizational changes.

\section{Essence of Integrated Reports}

In order to understand the essence of integrated reports, it is necessary to review once again their target audience and purpose of the information disclosed therein. I will clarify the view of this paper while reflecting on the views of the IIRC, Fasan, Barker and Kasim, and Stubbs and Higgins.

\subsection{Target Audience for Reports}

Based on the comparative studies of corporate reports by Fasan [9], Barker and Kasim [3], and Stubbs and Higgins, I will discuss the target audience of integrated reports. Fasan argues that the IIRC considers investors to be the target audience of integrated reports [9]. Barker and Kasim [3] bring up interested party, not limited to investors as the target audience of integrated reports from the UK Accounting Standard Steering Committee's The Corporate Report, which they quoted. Stubbs and Higgins [20] argue that as with sustainability reports, the target audience of integrated reports is stakeholders.

As clarified in Section 2, the IIRC [13] states that the target audience of integrated reports is providers of financial capital, but integrated reports also include information disclosure to stakeholders. In other words, this paper recognizes that the argument by Fasan [9] that the target audience is limited to investors is misinterpretation. Rather, as Barker and Kasim [3] and Stubbs and Higgins [20] argue, the IIRC's view is that the target audience is stakeholders and it should be interpreted in that way.

With regard to the target audience, there are two problems. The first is the difference between interested party and stakeholders. The second is whether integrated reports are similar to financial reports or whether they should be considered an expansion of sustainability reports.

For the first problem, the target audience according to Barker and Kasim and that according to Stubbs and Higgins are different. Barker and Kasim [3] clarify a user-oriented perspective in The Corporate Report stating that information is disclosed to interested party. On the other hand, Stubbs and Higgins [20] argue that the target audience of integrated reports is stakeholders. What is the difference between interested party and stakeholders? As Ito [22] has already discussed, the concept of stakeholders differs from that of interested party. While interested parties demand harmonization of interests in relation to profit distribution, stakeholders offer information related to strategies and management to corporations. Dill [8] points out that "the interest of external members (stakeholders, author) has changed greatly, from short-term interests such as product prices and quality to matters of long-term strategic significance including environmental preservation, overseas investment policies, and response to employment problems" [7]. In other words, Dill's view is that corporate managers should incorporate such stakeholders' interests in strategy formulation and business management.

The second problem is whether the origin of integrated reports is in financial reports or sustainability reports. Fasan [9] points out that both financial reports and integrated reports disclose information to investors and that financial reports evolved into integrated reports. Conversely, Barker and Kasim [3] argue that the original target audience of financial reports had been interested parties and therefore, the origin of integrated reports is financial reports. Stubbs and Higgins [20] state that integrated reports developed from sustainability reports. Figure 1 shows the relationships mentioned above. 
View of Fasan

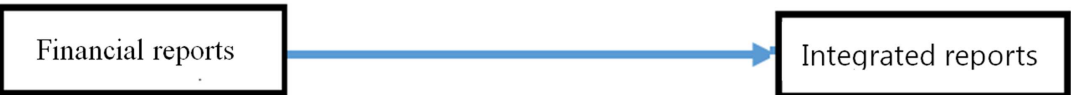

View of Barker and Kasim

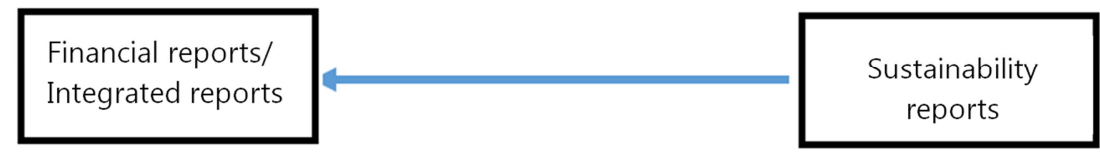

View of Stubbs and Higgins

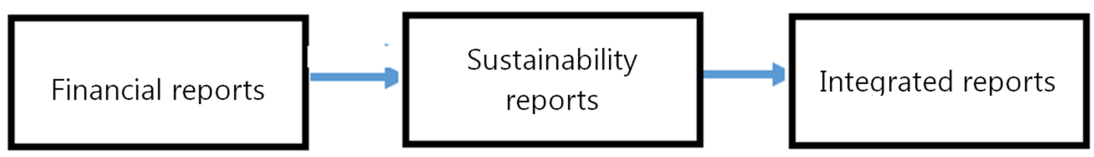

Source: created by the author.

Figure 1. Paradigm Shift on the Target Audience of Corporate Reports.

Fasan's [9] argument seeks similarity in the target audience of corporate reports, but his understanding of integrated reports differs from that of the IIRC. Because Fasan misunderstands the IIRC view, this paper will not take up his view. Below, this paper will consider the respective views of Barker and Kasim and Stubbs and Higgins on the paradigm shift.

Why do Barker and Kasim [3] point out that a paradigm shift from sustainability reports to financial reports has occurred? According to the UK Accounting Standard Steering Committee's The Corporate Report [1], investors and financial institutions require information for investment and repayment. Employees seek information to figure out guarantee of employment. Analysts need the same information as investors. Traders need information not only on payment ability, but on long-term sustainability as well. Customers need information related to the provision of products and services. The government requires information to estimate the impact on tax collection. Local residents want information on what corporations do for society. In other words, the aim of corporate reports is to disclose information to resolve conflicting interests between corporations and interested party. From the viewpoint of information users other than investors, financial reports and integrated reports can be interpreted to have the same root. Therefore, Barker and Kasim would be considered that a shift from sustainability reports to financial reports and integrated reports has occurred.

Stubbs and Higgins [20] argue that the target audience of integrated reports is stakeholders, to whom information is disclosed. On this point, they share the same view as the IIRC. However, Stubbs and Higgins anticipate that the disclosed information is not simply for stakeholders, but that the creation of integrated reports will bring about organizational changes in corporations. In this sense, Stubbs and Higgins point out that a shift has occurred from sustainability reports to integrated reports.

The difference between the paradigm shift according to Barker and Kasim and Stubbs and Higgins is whether financial reports and integrated reports share a root. Their views are the same on the point that the aim of sustainability reports and integrated reports is to disclose information to stakeholders. How financial reports differ from sustainability reports and integrated reports is whether they include stakeholder engagement. The significant difference between financial reports and integrated reports is whether such engagement is conducted or not.

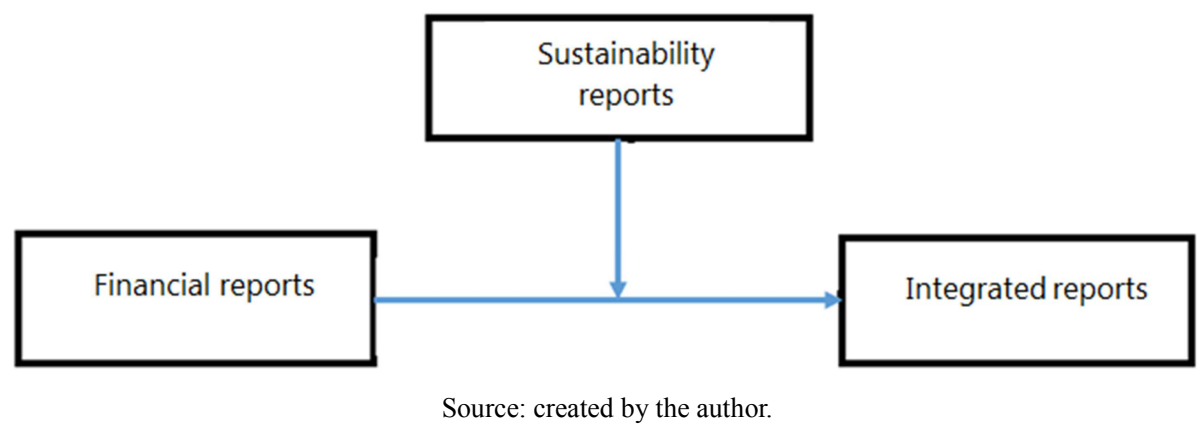

Figure 2. Paradigm Shift on Target Audience Proposed in this Paper.

This paper has made clear the arguments of Fasan, Barker and Kasim, and Stubbs and Higgins. In contrast with their 
arguments, the paradigm shift in Figure 2 would have occurred and our clarification of the argument in Figure 2. Financial reports must be created for information disclosure externally by law. However, financial reports, which mainly include past information, are no longer able to respond to the decision-making needs of investors. Stakeholders have become interested in the response of corporations to environmental issues and social responsibility problems, which do not necessarily connect directly to financial reports. And corporations have been reporting on such problems voluntarily in the form of sustainability reports. They can disclose through sustainability reports CSR information that cannot be disclosed in financial reports alone. However, while it seems as if the problem could be resolved by releasing both types of reports, a new problem has emerged. The information in financial reports and sustainability reports are not coherent, thereby causing a loss of trust from investors as well as stakeholders. Moreover, the visualization of the value creation process and strategies has led to the necessity of engagement with stakeholders. Integrated reports have appeared as a solution to these problems.

\subsection{Reporting Purpose}

Fasan [9] points out that the reporting purpose of integrated reports is to provide information to investors, while the IIRC [13] and Barker and Kasim [3] are of the view that the purpose is engagement with stakeholders not limited to investors. Furthermore, Stubbs and Higgins [20] reveal their view that not only are integrated reports used for stakeholder engagement, but they can also be used for managers for organizational changes. This paper will discuss these views below.

There is a view that the information disclosure approach of sustainability reports can be divided into two categories from their reporting purposes [5], [19]. The two categories are the outside-in approach and inside-out approach. The outside-in approach is to report information in order to disclose that a corporation is in compliance with external laws and

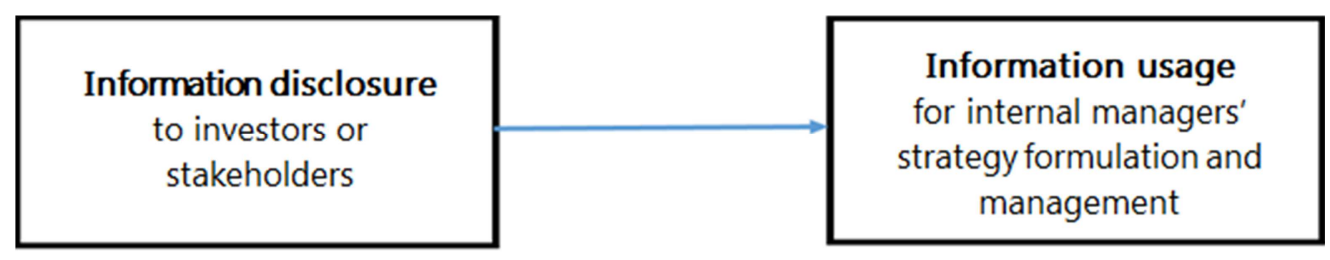

Source: created by the author.

Figure 3. Paradigm Shift in the Reporting Purpose.

Lastly, the paradigm shifts in corporate reports as it is argued in this paper will be considered (see Figure 3). The discussion up to now has focused on whether the reporting purpose of integrated reports is information output to investors and stakeholders. Finance and accounting research and CSR research focus on response to the information needs of investors and stakeholders in the form of information disclosure. This paper argues that rather than focusing on discussion on such information disclosure, focus should shift regulations. The inside-out approach is to provide internal management information to stakeholders. The outside-in and inside-out approaches are expressed as pull and push approaches by Stubbs and Higgins [20]. Financial reports which are released for the purpose of disclosing information to investors must follow accounting standards, which falls under the outside-in approach. In contrast with that, sustainability reports aimed at engaging with stakeholders are created to disclose internal information; therefore, is of an inside-out approach.

The integrated reports, according to the argument by Fasan [9], are of an outside-in approach in the sense that they must comply with the IIRC framework. Furthermore, Barker and Kasim [3] consider integrated reports are of a twin-approach with elements of both outside-in and inside-out approaches. This is because while financial reports are of an outside-in approach, sustainability reports are of an inside-out approach.

Stubbs and Higgins conducted interviews based on the hypothesis that organizational changes would take place in the process of creating integrated reports. This indicates that Stubbs and Higgins thought not simply about the disclosure of internal information, but also of information usage by internal managers for organizational changes occurring in the process of creating integrated reports. In other words, the essence of integrated reporting is not only external information disclosure in outside-in and inside-out approaches, but it is also useful for corporations' organizational changes.

From the viewpoint of stakeholder engagement, engagement aimed at the disclosure of internal information such as through sustainability reports had been the conventional method of engagement. However, stakeholder engagement through integrated reports is the dialog with stakeholders about strategies and value creation in order to formulate strategies. Stakeholder engagement should not be limited to external information disclosure; but it is necessary to disclose information keeping in mind the use of information for a corporation's organizational changes and strategy formulation [21].

to the discussion that the reporting purpose of integrated reports is information input for corporate managers' strategy formulation and management. For managerial accounting research, the use of information for internal managers' strategy formulation and management is essential.

\section{Conclusion}

This paper discussed the paradigm shift of corporate reports. 
There are researchers who argued that integrated reports were a paradigm shift from financial reports. This paper discussed the paradigm shift of corporate reports. This paper pointed out that there are two types of paradigm shifts: from financial reports to integrated reports and from sustainability reports to integrated reports. Our opinion is a paradigm shift from financial reports to integrated reports effected sustainability reports. Then this paper proposed that the significance of corporate reports has not changed so far. It is true that the effectiveness of sustainability reports to the corporate reports has been too much.

There are different opinions about the end-user of integrated reports. One opinion is that the end-users are investors, the other opinion is that they are an end-user is stakeholders. The opinion of Investors is that it is important to disclose a financial information and a nonfinancial information for investor's decision making. On the other hand, the opinion of stakeholders is that it is important to engage financial information and nonfinancial information for stakeholders. Our opinion is that end-users are not only stakeholders, but also the management of the firm disclosed, because management can use the information of stakeholder engagement for strategic formulation and management. Not only can stakeholders learn about strategies, managers can obtain information from stakeholders for strategy formulation. Utilizing information for strategy formulation is the major difference between sustainability reports and integrated reports.

Financial reports and sustainability reports focus on external information disclosure. On the other hand, in the reporting purpose of integrated reports a paradigm shift, from simple information disclosure to stakeholders to information usage for internal managers' strategy formulation and management, has occurred. In short, this paper clarifies that the essence of integrated reports is the disclosure of information to stakeholders and use of information by internal managers. This point makes a major difference between our view and the IIRC framework, which limits the purpose to information disclosure.

\section{Acknowledgements}

The authors would like to thank Professor Rohe, G. at Aichi Gakuin University for revising English of this article. This work was supported by JSPS KAKENHI grant Number 18K01940.

\section{References}

[1] ASSC (1975) The Corporate Report, Accounting Standard Steering Committee.

[2] Adams, S. and Simnett, R. (2011) Integrated Reporting: An Opportunity for Australia's Not-For-Profit Sector, Australian Accounting Review, Vol. 21 No. 3, pp. 292-301.

[3] Barker, R. and T. Kasim (2016) Integrated Reporting: Precursor of a Paradigm Shift in Corporate Reporting? in Mio, C. (2016) "Integrated Reporting: A New Accounting Disclosure", Palagrave Macmillan.

[4] Brown, J. and J. Dillard (2014) Integrated Reporting: On the Need for Broadening Out and Opening Up, Accounting,
Auditing \& Accountancy Journal, Vo..27 NO. 7, pp. 1120-1156.

[5] Burritt, R. L. \& S. Schaltegger (2010), Sustainability Accounting and Reporting: Fad or Trend? Accounting, Auditing \& Accountability Journal, Vol.23, No.7, pp.829-846.

[6] Cheng, M., Green, W., Conradie, P., Konishi, N. and Romi, A. (2014) The International Integrated Reporting Framework: Key Issues and Future Research Opportunities, Journal of International Financial Management \& Accounting, Vol. 25 No. 1, pp. 90-119.

[7] Cox, C. C. (2007) Speech by SEC Chairman: Closing Remarks to the Second Annual Corporate Governance Summit, https://www.sec.gov/news/speech/2007/spch032307cc.htm $(2017 / 4 / 1)$.

[8] Dill, W. R. 1975. Public Participation in Corporate Planning: Strategic Management in a Kibitzer's World. Long Range Planning 8(1), pp. 57-63.

[9] Fasan, M. (2013) Annual Reports, Sustainability Reports and Integrated Reports: Trends in Corporate Disclosure, in Ratti, S. (2013) Integrated Reporting: Concepts and Cases that Redefine Corporate Accountability, Splrnger International.

[10] Frías-Aceituno, J. V., Rodríguez-Aríza, L. and García-Sánchez, I. M. (2014) Explanatory Factors of Integrated Sustainability and Financial Reporting, Business Strategy and the Environment, Vol. 23 No. 1, pp. 56-72.

[11] Hampton, R. (2012) Brace Yourself: More Regulatory Changes, Accountancy SA, May, pp. 22-23.

[12] Haller, A. (2016) Value Creation: A Core Concept of Integrated Reporting, in Mio, C. (2016) Integrated Reporting: A New Accounting Disclosure, Palagrave Macmillan.

[13] IIRC (2013) The International $<I R>$ Framework, International Integrated Reporting Council.

[14] Kraten, M. (2017) Transforming Integrate Reporting into Integrated Information Management Accountants, The CPA Journal, Vol. 87, Issue 7, pp. 6-9.

[15] Koga, C. (2015) The Judgment about Issues and Methods of Integrated Reporting Research and Research Agenda in the Future (in Japanese), Accounting, Vol.188, No.5, pp. 1-15.

[16] Mark W. M. and M. P. Thomas (2015) The MultiCapital Scorecard, Sustainability Accounting, Management and Policy Journal, Vol.6 Issue: 3, pp. 425-438.

[17] Roberts, R. W. (1992) Determinants of Corporate Social Responsibility Disclosure, Accounting, Organizations and Society, Vol. 17 No. 6, pp. 595-612.

[18] Owen, G. (2013) Integrated Reporting: A Review of Developments and their Implications for Accounting Curriculum, Accounting Education, Vol.22, No.4, pp. 340-356.

[19] Schaltegger, S. (2012) Sustainability Reporting in the Light of Business Environments: Linking Business Environment, Strategy, Communication and Accounting, Discussion Paper.

[20] Stubbs, W. and C. Higgins (2014) Integrated Reporting and Internal Mechanisms of Change, Accounting, Auditing \& Accountability Journal, Vol. 27, No. 7, pp. 1068-1089.

[21] Watson, A. (2011) Financial Information in an Integrated Report: A Forward Looking Approach, Accountancy SA, December, pp. 14-17. 
[22] Ito, K. (2016) From Interest Adjustment for Interested Parties to Engagement with Stakeholders (in Japanese), Disclosure News, Vol. 32, pp. 123-128.
[23] Ito, K. and Nishihara, T. (2016) Disclosure and Usability of Information on Integrated Report of Eizai, (in Japanese), Kaikeigaku Kenkyu, No. 43, pp.1-26. 